\title{
Study on Ozone/Fenton Reagent Co-processing of Wheat Straw Pulp Hypochlorite Bleaching Wastewater
}

\author{
Zhengshun Wang ${ }^{1}$, a , Yingjie Liu ${ }^{1}$ \\ ${ }^{1}$ Key Laboratory of Pulp and Paper Science \& Technology of Ministry of Education, \\ Qilu University of Technology, Jinan, China, 250353 \\ awzsylq@aliyun.com
}

\section{Keywords: Ozone /Fenton reagent, Hypochlorite bleaching wastewater, Treatment}

\begin{abstract}
This experiment explores to pre ozone used for wheat straw pulp hypochlorite bleaching wastewater treatment of optimum oxidation time, initial $\mathrm{pH}$ of Fenton reaction water, $\mathrm{H}_{2} \mathrm{O}_{2} / \mathrm{FeSO}_{4}$ dosing ratio, reaction time on Fenton method depth treatment effect of bleaching effluent. The bleaching wastewater is pretreated with the ozone concentration $2.9 \mathrm{mg} / \mathrm{l}$. The experimental results show that the best pretreatment time of ozone is 30min. The removal rates of CODcr, TOCcr and chroma were $53.9 \%, 82.8 \%$ and $68 \%$ respectively with ozone pretreatment. The ozone oxidation process has a good effect on the removal of organic substances in wastewater. Treatment of straw pulp hypochlorite bleaching wastewater by Fenton reagent, the experimental results show that CODcr removal rate of wastewater is about $74 \%$, the chroma is above $87.5 \%$, and the supernatant is colorless under the initial ph5.6, $\mathrm{H}_{2} \mathrm{O}_{2}$ of $1 \mathrm{ml}, \mathrm{n}\left(\mathrm{H}_{2} \mathrm{O}_{2}\right): \mathrm{n}\left(\mathrm{Fe}^{2+}\right)=4$, $\mathrm{FeSO}_{4}$ dosage $2 \mathrm{ml}$, reaction temperature $20^{\circ} \mathrm{C}$, reaction time $40 \mathrm{~min}, 0.1 \%$ PAM.
\end{abstract}

\section{Introduction}

With the international community's attention to environmental issues, as well as the improvement of people's living standards, people pay more and more attention to the environment of their lives. Papermaking enterprises is a major wastewater production. Researching and developing a good treatment effect and low cost of wastewater treatment method is particularly important from the perspective of the future development and survival. The research and development of new wastewater treatment technology has opened up a new way for the treatment of papermaking wastewater.

Ozone wastewater treatment technology is a new technology. No two pollution is produced in the process, it is a more and more popular wastewater treatment technology. But the technology is not mature enough in the practical application. Fenton oxidation treatment technology has many advantages, but its own processing cost is higher and the $\mathrm{Fe}^{2+}$ content is higher in the treated wastewater process. So it is of great practical significance to find a kind of low cost and good effect of wastewater treatment and to study the reactive mechanism of Fenton and other processes. This paper mainly studies of ozone and Fenton reagent co-treatment process of wheat straw pulp hypochlorite bleaching wastewater.

\section{Experimental}

Materials. The wastewater from a paper mill wheat straw pulp hypochlorite bleaching wastewater, laboratory stored for 3months, water is dark brown and smell.

Instruments and Chemicals. Oxyhydroxide harmless handler (Qingdao ODO Environmental Technology Development Co., Ltd. China); Ozone Generator (Fujian Hui Wei Environmental Protection Technology Co., Ltd. HW-OW-50,China);Oven( Shanghai SHULI instrument and Meter Co., Ltd., china); Electronicbalance PTF-A100, Fuzhou Hua Zhi Science Co., Ltd., China; PH acidity meter PHS-25C(Shanghai Peng Shun Scientific Instrument Co., Ltd., China); COD determinator: DRB200 DR1010 (Qingdao Hash company, China); Total organic carbon analyzer: TOC-LCPH 
(SHIMADZU analysis instrument division, China); BOD determinator (Germany WTW China Technical Service Center, Germany).

$\mathrm{H}_{2} \mathrm{O}_{2}(30 \%)$, AR, 8.8mol/L; $\mathrm{FeSO}_{4}$ solution, $10 \%$, 0.359mol/L; 5\% $\mathrm{H}_{2} \mathrm{SO}_{4}$ solution; $\mathrm{NaOH}(5 \%)$ solution; PAM solution:Anion type, molecular weight 12 million, industrial grade, formulated into $0.1 \%$ solution (the drugs were for Tianjin Kermel Chemical Reagent Co., Ltd, prepare by oneself).

Experimental Method. Determination of the concentration of ozone water produced by ozone generator. Determination of iodine content, the ozone concentration of ozone generator is $2.9 \mathrm{mg} / \mathrm{l}$.

Wastewater Pretreatment. The wastewater was filtered by 150 mesh filtering net, and the following experiments were carried out with the pretreated wastewater.

Ozone Pre-Oxidation. After the filtration, the wastewater was treated with ozone generator, and then the waste water was used for the detection of the indicators in the fixed time period.

Fenton Reagent Oxidation. Get the Waste water after ozonation, dosage of cylinder volume $100 \mathrm{ml}$ to the beaker, adding proper amount of $\mathrm{FeSO}_{4}$ solution, rapid mixing, and then adding an appropriate amount of $\mathrm{H}_{2} \mathrm{O}_{2}$ solution, rapid mixing and at the same time pay attention to the change of $\mathrm{pH}$, available configuration of dilute sulfuric acid to adjust, after 30 minutes, with prepared sodium hydroxide solution to adjust $\mathrm{pH}$ to 7 , then add a certain amount of PAM flocculation, standing about 5 minutes and the supernatant were detected. From the economic cost and oxidation effect of consideration, investigation system in different Fenton reagent addition CODcr changes, and to determine the Fenton reagent reaction of the best initial $\mathrm{pH}$.

\section{Results and Discussion}

Wastewater Pretreatment. After pretreatment of wastewater, the water quality of the supernatant was detected, and the results of the effluent were shown in Table 1.

Table 1. The water indictors of the supernatant after pretreatment.

\begin{tabular}{|c|c|c|c|c|}
\hline CODcr/ (mg/l) & TOCcr/ (mg/l) & $\mathrm{pH}$ & suspended solid/ $(\mathrm{mg} / \mathrm{L})$ & chroma/ times \\
\hline 1063 & 912.30 & 6.19 & 126 & 200 \\
\hline
\end{tabular}

Ozone Pretreatment. The effects of $\mathrm{O}_{3}$ oxidation time on CODcr, TOCcr and chroma of wastewater, as shown in Fig. 1.

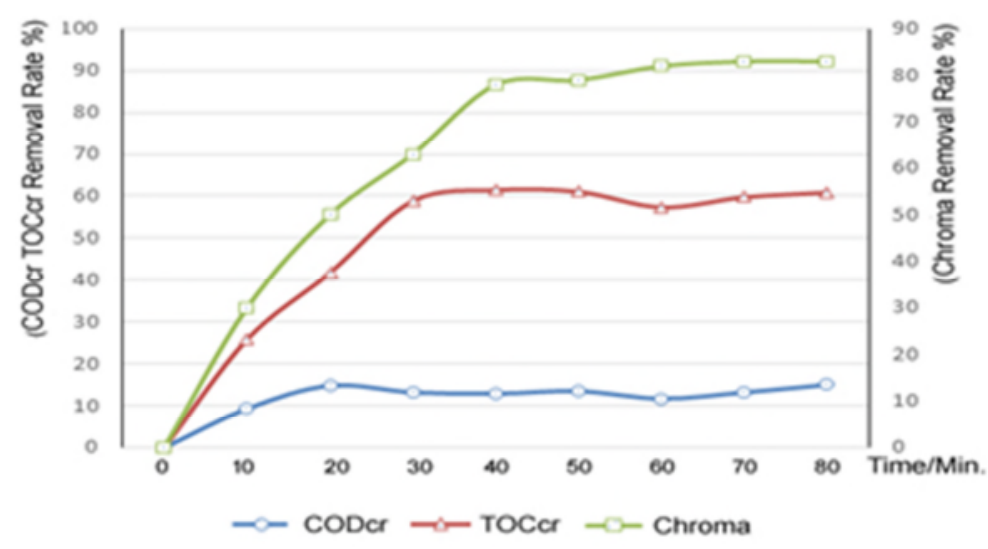

Fig. 1 The effects of $\mathrm{O} 3$ oxidation time on CODcr, TOCcr and chroma of wastewater.

Can be seen from Fig. 1, the removal rate of TOCcr, CODcr and chroma of wastewater are increasing with the increase of ozone oxidation reaction time in the reaction time of 40 minutes. However, after 40min, the removal rate remained essentially unchanged. The removal rate of CODcr remained at about $15 \%$, TOCcr $63 \%$, chroma $80 \%$. The reasons can be summarized as follows:Ozone and hydroxyl radicals generated in the reaction of ozone has strong oxidation. At the beginning of the reaction, the concentration of organic pollutants in wastewater is large, so the reaction is fast. With 
extension of reaction time, the concentration of the organic matter in the wastewater continue to decline, but with limited processing capability of ozone reaction to a certain degree, the wastewater of CODcr and TOCcr will no longer occur change. Therefore, the ozone pre-oxidation time is more suitable for 40min.

Treatment of Wastewater with Fenton Reagent. Take $100 \mathrm{ml}$ ozone pretreatment $90 \mathrm{~min}$ wastewater 4, add $6 \mathrm{ml}$ prepared $\mathrm{FeSO}_{4}$ solution, and then add $0.15 \mathrm{ml}$ of $30 \% \mathrm{H}_{2} \mathrm{O}_{2}$ solution. The initial $\mathrm{pH}$ of wastewater is regulated by dilute sulfuric acid. The effects of different initial $\mathrm{pH}$ on the treatment of wastewater are investigated. The results are shown in Fig. 2.

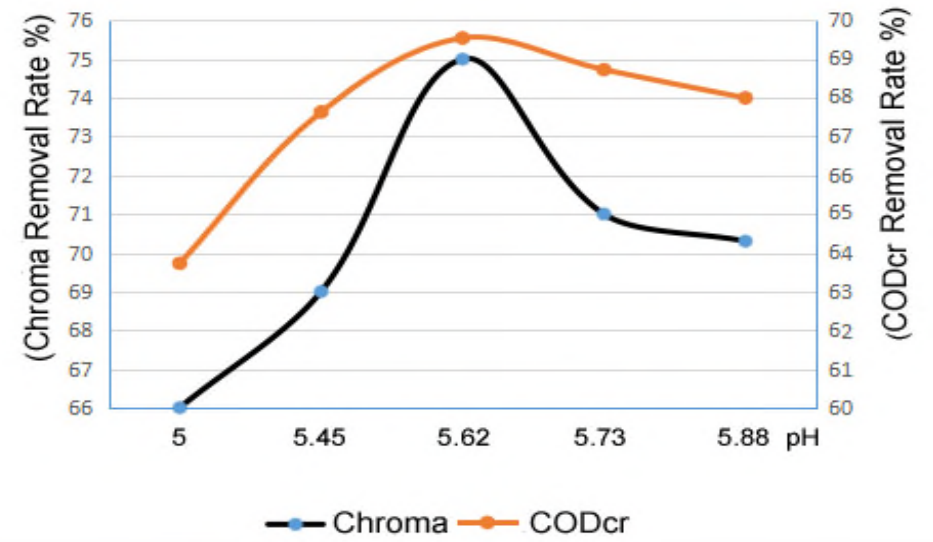

Fig. 2 The Effect of different initial pH changes on CODcr and chroma of wastewater.

Can be seen from Fig. 2 and Fig. 3, the initial pH has a great influence on the oxidation treatment of Fenton wastewater. Experimental results show that the removal rates of CODcr and chroma were $69.6 \%$ and $75 \%$ respectively when $\mathrm{pH}$ was close to 5.6 and the removal rate decreased when the $\mathrm{pH}$ was higher than 5.6. This shows that the treatment effect of wastewater is the best when ph5.6. Comprehensive analysis is as follows, Fenton oxidation reaction is generally in the acidic ph4-6 environment is the most suitable conditions. The reaction rate of Fenton was relatively fast under the acid condition. When $\mathrm{pH}$ was 5.6, the reaction rate was the fastest, and the generation rate of hydroxyl radical was the highest. The reaction rate becomes slow with the increase of $\mathrm{pH}$ value. This is because of the occurrence of two side effects: first, there will be part of the $\mathrm{Fe}^{2+}$ is oxidized to $\mathrm{Fe}^{3+}$ with the progress of the reaction. The catalytic effect of $\mathrm{Fe}^{3+}$ generated is far less $\mathrm{Fe}^{2+}$. This decrease the reaction rate; secondly, $\mathrm{H}_{2} \mathrm{O}_{2}$ is not stable and easy to be decomposed into water and oxygen under higher $\mathrm{pH}$ conditions. So we chose $\mathrm{pH}$ as 5.6 in this experiment.

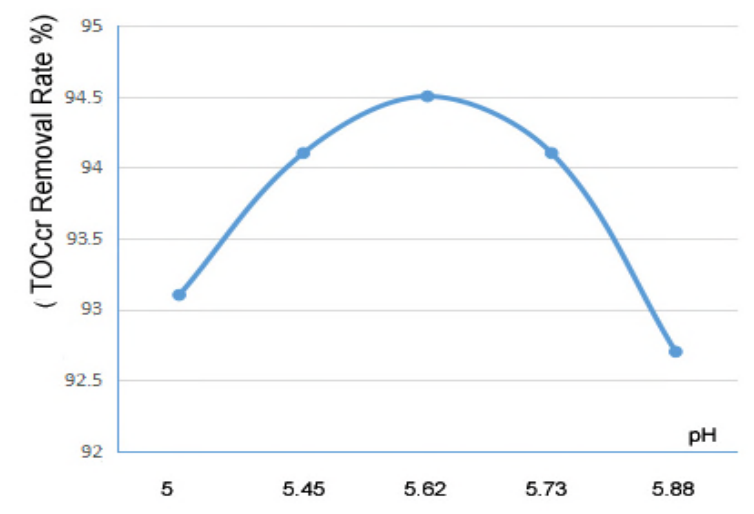

Fig. 3 The effect of different initial $\mathrm{pH}$ change on TOCcr of wastewater.

The Effect of $\mathrm{H}_{2} \mathrm{O}_{2} / \mathrm{FeSO}_{4}$ addition Ratio on Wastewater Treatment. Take ozone pretreatment $90 \mathrm{~min}$ wastewater, and then divided it in five, each take $100 \mathrm{ml}$, determination of wastewater $\mathrm{pH}$, with dilute sulfuric acid to adjust to the best ph5.6, to add different doses of $\mathrm{H}_{2} \mathrm{O}_{2}$ and $\mathrm{Fe}^{2+}$ respectively. To 
join the $\mathrm{Fe}^{2+}$ stirring 5 min to uniform, then add to $30 \% \mathrm{H}_{2} \mathrm{O}_{2}$ to react for $40 \mathrm{~min}$. At the end of the reaction, join $\mathrm{NaOH}$ solution to adjust the effluent $\mathrm{pH}$ to 7 directly, then add to $0.1 \%$ PAM and mixing flocculation and static precipitation for $30 \mathrm{~min}$, the supernatant was determined.

As can be seen from Fig. 4, the removal rate of CODcr and TOCcr varies with the change of $\mathrm{H}_{2} \mathrm{O}_{2}$ $/ \mathrm{FeSO}_{4}$ ratio. There is a wave of the CODcr removal rate with the $\mathrm{H}_{2} \mathrm{O}_{2} / \mathrm{FeSO}_{4}$ ratio, the first increase and then decrease and in the final $\mathrm{pH}$ reached 4.1 to reach the maximum. At the same time, the removal rate of TOCcr is the same point $\mathrm{pH} 4.1$. when the ratio to about 4, the removal rate of CODcr reached about $72 \%$ and TOCcr $77 \%$. The reasons are as follows, when the amount of $\mathrm{H}_{2} \mathrm{O}_{2}$ is too low to produce sufficient amounts of $\cdot \mathrm{OH}$ to participate in the reaction. The generation of $\cdot \mathrm{OH}$ gradually increased with the amount of $\mathrm{H}_{2} \mathrm{O}_{2}$ added, so that the removal rate of CODcr gradually increased. When continue to increase of $\mathrm{H}_{2} \mathrm{O}_{2}$ dosage, the organic matter oxidation has been completed of the system, then the $\mathrm{H}_{2} \mathrm{O}_{2}$ will be Invalid decomposed and there will be reaction $\mathrm{R}+\cdot \mathrm{OH}=\mathrm{ROH}$ ( $\mathrm{R}$ is organic groups). The first $\mathrm{OH}$ production occurred is devoid of. Not only an excess of $\mathrm{H}_{2} \mathrm{O}_{2}$ will cause the remnants of the CODcr increase, but also lead to the $\mathrm{H}_{2} \mathrm{O}_{2}$ 's own invalid decomposition. Therefore, it is very necessary to control the amount of $\mathrm{H}_{2} \mathrm{O}_{2}$ in order to save processing costs and to achieve wastewater reuse standards. The optimum dosage of $\mathrm{H}_{2} \mathrm{O}_{2}$ is $88 \mathrm{mmol} / \mathrm{l}$.

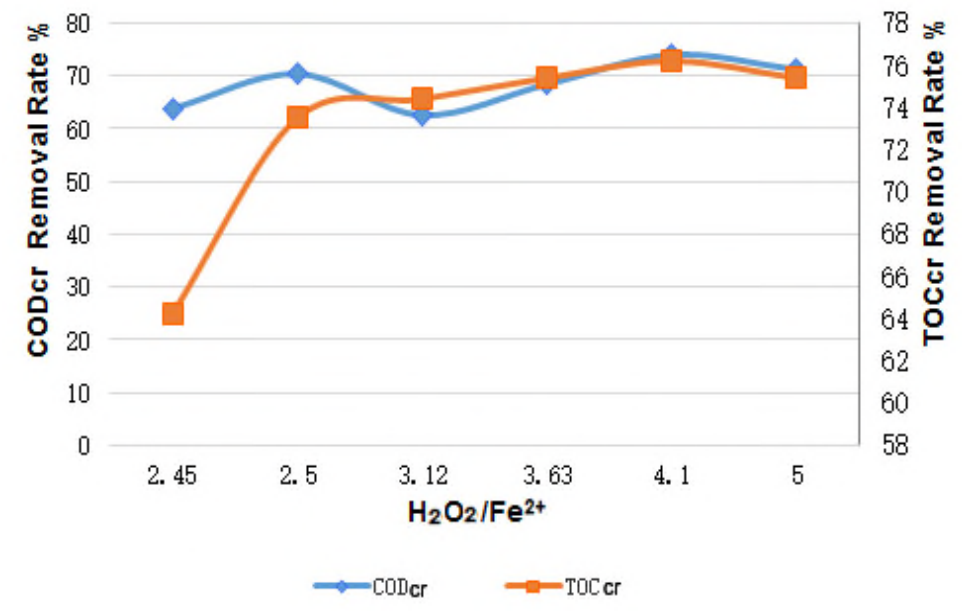

Fig. 4 The effect on the CODcr and TOCcr removal rate of the $\mathrm{H} 2 \mathrm{O} 2$ /FeSO4 ratio.

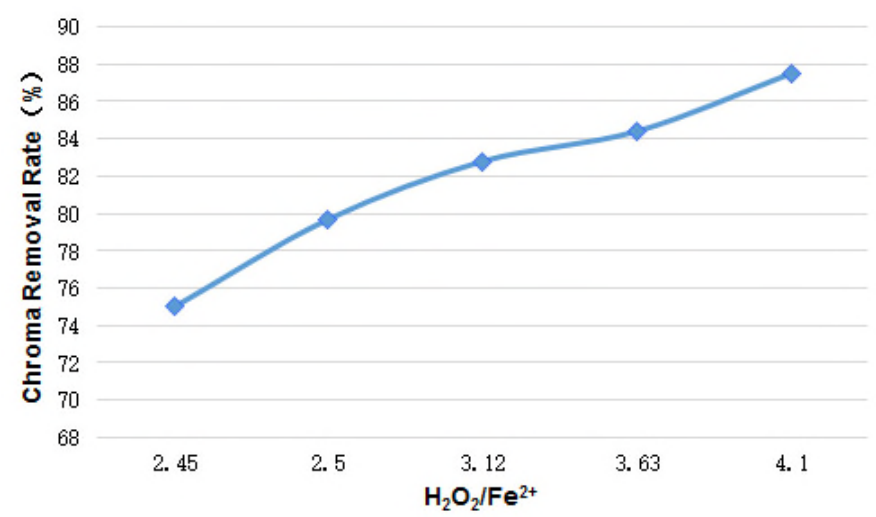

Fig. 5 The effect on the chroma removal rate of the $\mathrm{H} 2 \mathrm{O} 2 / \mathrm{FeSO} 4$ ratio.

As can be seen from Fig. 5, the dosage of $\mathrm{Fe}^{2+}$ has a great influence on the oxidation treatment effect of Fenton. The removal rate of chroma increases with the ratio of $\mathrm{H}_{2} \mathrm{O}_{2} / \mathrm{FeSO}_{4}$.

In the Fenton treatment system, $\mathrm{Fe}^{2+}$ is a necessary condition for the production of free $\mathrm{OH}$ radicals. $\mathrm{H}_{2} \mathrm{O}_{2}$ is difficult to break down to product. $\mathrm{OH}$ without $\mathrm{Fe}^{2+}$. When the concentration of $\mathrm{Fe}^{2+}$ is relatively low, the reaction $\mathrm{OH}$ is very low, and the speed is slow, which limits the reaction speed of the system. Therefore, the removal rate of CODcr is relatively low. The number of $\mathrm{OH}$ generated is also increasing with the concentration of $\mathrm{Fe}^{2+}$, and the removal rate of CODcr is increasing. When the amount of $\mathrm{Fe}^{2+}$ added is too high, a large number of $\mathrm{Fe}^{2+}$ make $\mathrm{H}_{2} \mathrm{O}_{2}$ decompose fast and produce a 
large number of $\cdot \mathrm{OH} . \mathrm{OH}$ can not react with the organic pollutants in the system and aggregate and mutual react and come into being water and $\mathrm{O}_{2}$. A part of the initial production of the $\mathrm{OH}$ is consumed and reduced the utilization of $\mathrm{H}_{2} \mathrm{O}_{2}$. Therefore the choice of $\mathrm{H}_{2} \mathrm{O}_{2} / \mathrm{Fe}^{2+}$ ratio equal to 4 is more appropriate.

The Effect of Reaction Time on the Treatment of Wastewater. The initial $\mathrm{pH}$ of water sample after ozone treatment was 5.8. Fixed $\mathrm{n}\left(\mathrm{H}_{2} \mathrm{O}_{2}\right)$ :n $\left(\mathrm{Fe}^{2+}\right)=4, \mathrm{FeSO}_{4}$ dosage was $6 \mathrm{ml}, \mathrm{H}_{2} \mathrm{O}_{2}$ dosage was $1 \mathrm{ml}$. The reaction temperature is room temperature. The reaction time was set to $10,20,30,40,50 \mathrm{~min}$ for the experiment, and the reaction results were shown in Fig. 6.

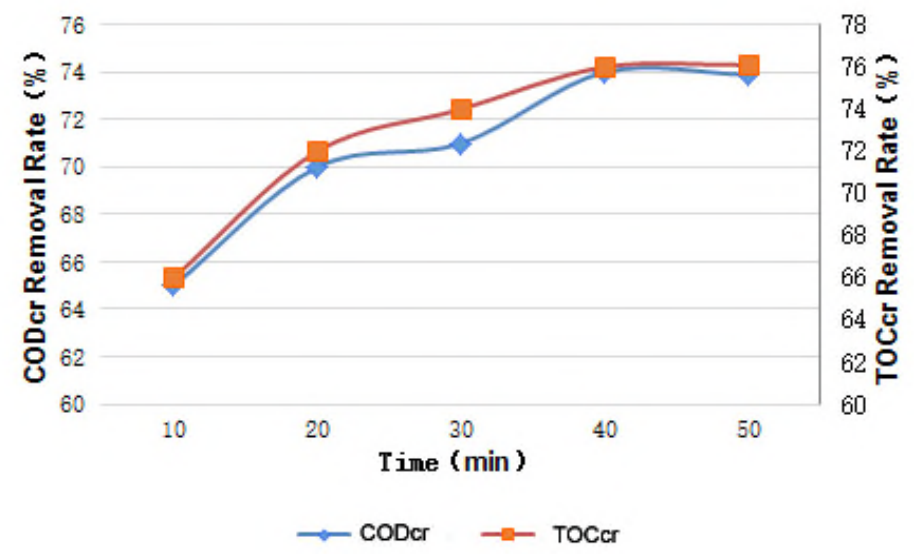

Fig. 6 The effect on the removal rate of CODcr and TOCcr of different reaction time.

As can be seen from Fig. 6, the removal rates of CODcr and TOCcr are increasing with the increasing reaction time. The removal rate reached $73.7 \%$ and $76.2 \%$ respectively when the reaction time was 40 minutes. CODcr and TOCcr removal rate changes little with the reaction time increase continued. Moreover, the slope of the initial stage of the reaction is larger. This is because of the higher concentration of organic matter in the early stage of the reaction, the reaction rate is the fastest. As the reaction is carried out, the concentration of organic matter in the waste water is reduced, and the reaction speed is slowed down. When the reaction was carried out to about 40min, the reaction rate of the system was obviously slowed down, which showed that the oxidation reaction of the system was very good, and the increase of reaction time had no effect.

Reaction time reflects the reaction process. The reaction time is insufficient to cause the oxidation of incomplete. The reaction time is too long will cause the reduction of processing efficiency. In the actual engineering operation, the equipment cost and operation cost will be increased, which makes the system lack of maneuverability. So to determine the most appropriate response time should be controlled at about $40 \mathrm{~min}$.

\section{Conclusion}

This experiment explores to pre ozone used for wheat straw pulp hypochlorite bleaching wastewater treatment of optimum oxidation time, initial $\mathrm{pH}$ of Fenton reaction water, $\mathrm{H}_{2} \mathrm{O}_{2} / \mathrm{FeSO}_{4}$ dosing ratio, reaction time on Fenton method depth treatment effect of bleaching effluent. The bleaching wastewater is pretreated with the ozone concentration $2.9 \mathrm{mg} / \mathrm{l}$. The experimental results show that the best pretreatment time of ozone is 30min. The removal rates of CODcr, TOCcr and chroma were $53.9 \%, 82.8 \%$ and $68 \%$ respectively with ozone pretreatment. The ozone oxidation process has a good effect on the removal of organic substances in wastewater. Treatment of straw pulp hypochlorite bleaching wastewater by Fenton reagent, the experimental results show that CODcr removal rate of wastewater is about $74 \%$, the chroma is above $87.5 \%$, and the supernatant is colorless under the initial ph5.6, $\mathrm{H}_{2} \mathrm{O}_{2}$ of $1 \mathrm{ml}, \mathrm{n}\left(\mathrm{H}_{2} \mathrm{O}_{2}\right): \mathrm{n}\left(\mathrm{Fe}^{2+}\right)=4, \mathrm{FeSO}_{4}$ dosage $2 \mathrm{ml}$, reaction temperature $20^{\circ} \mathrm{C}$, reaction time $40 \mathrm{~min}, 0.1 \%$ PAM. 


\section{References}

[1] Y. Z. Zhao, Y. Y. Wu, Y. Li, Q. Zhao. Fenton- Study on hybrid wheat straw pulp middle stage wastewater treatment, Heilongjiang Pulp \& Paper. (2) (2008) 1-5

[2] F. R. Fu, Y. Q. Shi, L. B. Ding, A. X. Pan, F. Shi, G. G. Fang. Study on the treatment of chemical-mechanical pulp wastewater by Fenton advanced oxidation process. Tech. Prog. 12(4) (2010) 5-7.

[3] J. L. Liu, C. H. Tian, Y. Y. Wu, X. F. Li. Treatment of E-stage wheat straw pulp bleaching wastewater by Fenton oxidation. Paper Papermaking. 30(5) (2011) 6-7.

[4] L. R. Lei, Y. M. Li. Advances in the treatment of pulping wastewater by ozonation and Catalytic ozonation. China Papermaking. 32(5) (2011) 55-59. 